\title{
Treatment Algorithm for Patients With Gastric Adenocarcinoma: An Austrian Consensus on Systemic Therapy
}

\author{
EWALD WÖLL ${ }^{1}$, WOLFGANG EISTERER ${ }^{2}$, ARMIN GERGER ${ }^{3}$, THOMAS KÜHR ${ }^{4}$, \\ GERALD W. PRAGER ${ }^{5}$, HOLGER RUMPOLD ${ }^{6}$, HERBERT ULRICH-PUR ${ }^{7}$, \\ URSULA VOGL $^{8}$, THOMAS WINDER ${ }^{6}$, LUKAS WEISS $^{9}$ and RICHARD GREIL ${ }^{9}$ \\ ${ }^{1}$ Department of Internal Medicine, St. Vinzenz Hospital, Zams, Austria; \\ ${ }^{2}$ Department of Internal Medicine and Oncology, Klagenfurt Hospital, Klagenfurt, Austria; \\ ${ }^{3}$ Division of Clinical Oncology, Department of Internal Medicine, Medical University of Graz, Graz, Austria; \\ ${ }^{4}$ Department of Internal Medicine IV, Wels-Grieskirchen Hospital, Wels, Austria; \\ ${ }^{5}$ Department of Medicine I, Medical University of Vienna, Vienna, Austria; \\ ${ }^{6}$ Department of Internal Medicine II, Academic Teaching Hospital Feldkirch, Feldkirch, Austria; \\ ${ }^{7}$ Department of Internal Medicine I, Wilhelminenspital, Vienna, Austria; \\ ${ }^{8}$ Department of Internal Medicine I, Barmherzige Schwestern Hospital, Vienna, Austria; \\ ${ }^{9}$ Third Medical Department with Haematology, Medical Oncology, Haemostaseology, \\ Infectious Diseases and Rheumatology, Oncology Centre, Paracelsus Medical University Salzburg, Salzburg, Austria
}

\begin{abstract}
Despite recent advances in the treatment of gastric cancer, mortality related to this disease is still substantial. Surgery and chemotherapy represent the cornerstones of patient management. Targeted treatments that include antiangiogenic agents and the advent of immunotherapies can contribute to improved patient prognosis. Herein, we present an Austrian consensus on the systemic treatment of patients with gastric adenocarcinoma and lower gastroesophageal junction, including those with human epidermal growth factor receptor 2 (HER2)-positive disease. The consensus considers the curative setting, as well as first-line to late-line systemic treatment options in the palliative setting. For HER2-positive disease, first-line and second-line therapies are discussed, as well as HER2 testing. Potential future therapies are also listed, with a focus on anti-angiogenic treatments and checkpoint inhibition, that might provide a further step forward in the management of patients with gastric cancer.
\end{abstract}

This article is freely accessible online.

Correspondence to: Ewald Wöll, St. Vinzenz Hospital Zams, Sanatoriumstr. 43, A6511 Zams, Austria. E-mail: ewald.woell@ krankenhaus-zams.at

Key Words: Gastric cancer, adenocarcinoma, stomach, lower gastroesophageal junction, treatment algorithm, review.
Gastric cancer is one of the more common malignant diseases worldwide, although its incidence continues to decrease in the western world (1). Patient prognosis depends on a number of factors, including disease stage and histology, patient performance status, and the presence of comorbidities. Early stages and locally restricted disease allow for treatment with curative intent, while a palliative approach is called for in the metastatic or locally advanced and inoperable settings. Treatment modalities can be defined as surgery and systemic. Despite the substantial progress that has been made over the past decade, cancer-related mortality remains high, at $70 \%$.

This Austrian consensus on systemic therapy for gastric cancer was drawn up in the light of changes in perioperative management and new treatment options emerging for later lines. At an Expert Meeting that took place in Fuschl, Austria, on October 12, 2018, experts discussed a range of topics based on current treatment guidelines. The summary of the discussion is the basis of this treatment algorithm and replaces the previously published recommendations (2).

The recommendations discussed here are restricted to adenocarcinoma of the stomach and lower gastroesophageal junction (Siewert III).

\section{Curative Treatment}

For patients with good Eastern Cooperative Oncology Group performance status (i.e. ECOG PS 0-1), implementation of a perioperative treatment plan is mandatory from stage IB 
disease ( $\geq \mathrm{T} 2$ or $\mathrm{N}+$ ) onward. This necessitates preoperative discussion of each patient case by the Interdisciplinary Tumor Board. The first-choice treatment is perioperative chemotherapy according to the FLOT regimen [5-fluorouracil (5-FU), leucovorin, oxaliplatin, docetaxel] $(3,4)$. Data have demonstrated that responses to FLOT can be expected regardless of the histological subtype of the tumor (e.g. signet ring cell component $v s$. no signet ring cell component). Anthracycline-containing regimens such as epirubicin, oxaliplatin and capecitabine (EOX) and epirubicin, cisplatin with capecitabine (ECX) (5) have been shown not to be as effective and should not be used in the clinical setting. Deescalation strategies can be established once toxicities emerge.

The primary administration of granulocyte-colony stimulating factor along with FLOT is not mandatory, but it might be necessary in individual patients because the rate of neutropenia with FLOT can be as high as $50 \%$. In the AIO FLOT-4 trial (716 patients included), $90 \%$ of the patients received four preoperative FLOT doses as planned, but only $51 \%$ completed the four planned postoperative doses. Comorbidities and pre-existing neuropathy can impede or preclude the use of FLOT (3).

Alternative regimens for patients intolerant to FLOT include platinum-based doublets, such as modified FOLFOX or 5-FU, and leucovorin and oxaliplatin. In older patients, intravenous 5-FU offers advantages over oral treatment. In the FLOT study, addition of taxanes provided distinct benefits (3). However, findings in Asia from the JACCRO GC-07 phase III trial were not as clear-cut (6). Here, the difference between S-1/docetaxel and S-1 alone for relapsefree survival was significantly in favor of S-1/docetaxel, while the overall survival (OS) difference was not. However, these data do not influence treatment decisions for Caucasian patients. The interval between the last chemotherapy and surgery should be 4 to 6 weeks.

Although patients with ECOG PS $>1$ were not included in the FLOT study, there was no age limit, with a median age of 65 years. Therefore, age was not a decisive factor here. FLOT should be offered to patients with stage IB disease ( $\geq \mathrm{T} 2$ or $\mathrm{N}+$ ) or higher who have ECOG PS 0 or 1 . As trial data are lacking for patients with ECOG PS 2, the choice of treatment needs to be determined on an individual basis. If tumor-related symptoms are the cause of poor patient ECOG PS, this justifies an aggressive perioperative approach. Patients whose condition precludes treatment with a doublet regimen should primarily undergo surgery. It is important not to jeopardize surgery as a result of intensive neoadjuvant therapy. As the validity of the ECOG PS has limitations, the modified Frailty Score Index (7) can be helpful for estimation of the overall condition of an individual patient in clinical practice, although it has not been formally tested in preoperative studies.

In the primarily curative setting, adjustment of the subsequent treatment is called for only if progression occurs within 6 months, as this implies that the perioperative treatment counts as the first line of the palliative regimen. Persistent neuropathy can influence the choice of the subsequent therapy.

For patients who do not develop postoperative complications, the interval between surgery and the next follow-up visit in clinical practice is commonly 2 to 3 weeks. Ideally, no more than 4 to 6 weeks should elapse until the start of postoperative chemotherapy. If the patient's recovery within 2 months is not sufficient to allow for chemotherapy, a watch-and-wait strategy can be considered.

The degree of histological regression after neoadjuvant treatment does not affect the selection of the postoperative regimen. Furthermore, the treatment should be continued postoperatively irrespective of the degree of regression that has been achieved. Rather, patient fitness is the crucial factor that determines the next steps. No data have been obtained for treatment changes nor treatment discontinuation based on the degree of regression.

It can be assumed that the efficacy of the treatment is mainly based on the neoadjuvant part, as almost half of all patients are unable to complete their postoperative therapy $(5,8)$. Responses to neoadjuvant treatment should be viewed as prognostic rather than predictive. First and foremost, the perioperative therapy targets micrometastatic disease after removal of the primary tumor. The degree of regression might therefore be a surrogate marker for treatment efficacy with respect to metastases; however, this assumption needs to be explored in a prospective manner. Patients who undergo curative surgery and only experience disease stabilization with FLOT therapy should continue treatment.

Nowadays, patients who do not receive chemotherapy prior to the resection of their tumors should be the exception. Adjuvant chemotherapy can be offered to patients with locally advanced gastric cancer who have not received preoperative treatment as a result of their insufficient staging (9). Caucasian patients do not benefit from intensified postoperative chemotherapy $(10,11)$. Moreover, no evidence is available on the ideal number of cycles; clinical trials have suggested treatment durations of 6 months and up to 1 year in Caucasian and Asian patients, respectively (12).

Combined radiochemotherapy is an option after insufficient lymph node dissection in the context of emergency surgery (13). Patients who have undergone adequate lymph node dissection $(\mathrm{D} 1+, 2)$ and have not received preoperative therapy can be offered postoperative adjuvant chemotherapy. Based on published data, it appears that only patients who undergo inadequate lymph node resection will benefit from combined radiochemotherapy (9, $14,15)$. With respect to the type of chemotherapy, the only data available in the postoperative setting were obtained for fluoropyrimidine. The ARTIST trial investigated adjuvant chemotherapy versus concurrent chemoradiotherapy and did 
not show a difference in disease-free or overall survival. The subgroup of patients with node-positive disease who simultaneously underwent D2 dissection, however, showed improved disease-free survival (16).

Overall, the available evidence does not support solid recommendations concerning the role of radiotherapy in gastric cancer. Data from randomized studies will provide future information, although only on the comparison between combined radiochemotherapy and perioperative chemotherapy. For the time being, combined radiochemotherapy is an option for patients who have undergone primary surgery with inadequate lymph-node dissection; for those with adequate resection, no data-pool exists.

Ongoing phase III studies, from which the results are awaited, are investigating radiochemotherapy for gastroesophageal junction tumors. Until these are completed, patients with gastroesophageal junction tumors can be offered both radiochemotherapy and chemotherapy $(8,17)$. Moreover, in the human epidermal growth factor receptor 2 (HER2)-positive setting, ongoing phase III trials are evaluating chemotherapy plus trastuzumab and pertuzumab. In HER2-negative patients, chemotherapy plus ramucirumab is being tested (NCT02661971), as well as chemotherapy plus immune checkpoint inhibitors (NCT03221426). No statement can be made about these strategies at present.

\section{Palliative Setting}

HER2 testing as a prerequisite for palliative therapy. The therapy used for patients with advanced inoperable gastric cancer or metastatic gastric cancer is driven by their HER2 status. Patients with HER2 positivity defined by immunohistochemistry (i.e. IHC $3+$ or IHC $2+$ ) and positive by fluorescence or silver in situ hybridization are treated differently (see below). HER2 testing is therefore mandatory for these patients, although it is generally difficult due to the heterogeneity of tumors and the quality of the pre-analytics. Analysis of the Austrian GASTRIC-5 registry has revealed variations of $\sim 17 \%$ with respect to HER2 readings (18). Therefore, certified or quality-assured testing is called for. Pathologists should participate in inter-laboratory comparison trials, or ring trials, and strive for high-quality processing of their samples.

First-line treatment of HER2-negative disease. Treatment is indicated for patients with ECOG PS $\leq 2$. Patients with ECOG PS >2 should only be considered for treatment if their PS deterioration is actually tumor-related.

Several studies have compared triplets with doublets in the frontline setting for patients with HER2-negative disease. Triplets have provided higher response rates than doublets; however, for OS, the differences have been markedly less pronounced, while at the same time, triplet therapies have considerably higher toxicity rates. Therefore, the trend observed toward improved OS must be weighed against the adverse effects of these treatments. Improvements to progression-free survival (PFS) and OS that are obtained at the expense of tolerability to the treatment often do not appear justified in the palliative setting. As a consequence, doublets are generally preferred for palliative first-line therapy in clinical practice. The benefits that can be obtained from triplets can be expected in patients who are highly symptomatic or who require a rapid response due to a high tumor burden $(9,19)$. In all other patients, doublets should be preferred $(9,20,21)$. Monotherapy is an exception; if a patient is not fit enough to receive doublet chemotherapy, the question must be raised as to whether systemic treatment is appropriate in the first place.

Patient age, as such, is not a criterion for clinical decisions. It has been shown that FLOT can be used in older patients, albeit only in those who are deemed fit and who need a rapid response. FLOT or modified docetaxel, cisplatin and 5-FU (DCF) have greater practicability and exhibit less toxicity, and these should therefore be preferred to standard DCF. The available doublets comprise platinum-containing combination regimens including oral or intravenous fluoropyrimidine. Here, the FLO regimen has primarily been explored in older patients (22). For patients for whom platinum-containing treatments are contraindicated, phase III data have established 5-FU, leucovorin combined with irinotecan (FOLFIRI) as an alternative (11). Platinum combinations boast a greater wealth of data. In patients with pronounced neuropathy, which limits the use of platinum therapy, FOLFIRI is a valid option. Anthracycline-containing triplets (e.g. epirubicin, cisplatin, 5-FU, ECX) play a minor role, due to the increased likelihood of adverse events.

If no toxicity issues are expected, repeated administration of taxanes represents an option in the relapse setting, as long as they are accompanied by an adequate time interval after perioperative (curative) pretreatment, which should be at least 3 to 6 months. Grade 1 neuropathy is not a contraindication; however, the accuracy of the medical history examination greatly influences grading, in terms of the degree of limitations in the daily life of the patient.

Dual treatment with capecitabine plus oxaliplatin (CAPOX) or FOLFOX can replace FLOT for patients who do not require rapid response. However, in patients whose disease progresses within 3 months of perioperative FLOT administration, the treatment should be switched to FOLFIRI or to other second-line options (see below).

First-line treatment of HER2-positive disease. Assessment of HER2 status is generally performed at the time of the initial diagnosis of gastric cancer. Trastuzumab plus platinum/ fluoropyrimidine-containing chemotherapy doublets is the standard first-line treatment of HER2-positive gastric cancer. 
In addition to trastuzumab, platinum and fluoropyrimidine are recommended as backbones for first-line treatment. CAPOX, FLO, FOLFOX, and cisplatin/5-FU are commonly used in clinical practice, whereas cisplatin/capecitabine is less popular (23). Trastuzumab is administered intravenously. Chemotherapy should be limited to a maximum of six cycles, while trastuzumab treatment should be continued until progression (24).

In the perioperative setting, the use of trastuzumab is still under investigation, so the results of ongoing trials are awaited. One issue, however, is the omission of preoperative laparoscopy in patients with localized, HER2-positive gastric cancer who receive preoperative FLOT with curative intent, as the presence of peritoneal carcinomatosis requires palliative trastuzumab treatment. The incidence of peritoneal carcinomatosis increases steeply from stage T2 onwards; therefore, preoperative laparoscopy is recommended in these patients.

Second-line treatment of HER2-negative disease. Based on phase III data, ramucirumab plus paclitaxel constitutes the favored second-line strategy for HER2-negative disease (25). Other available options include single-agent options of ramucirumab (26), irinotecan $(27,28)$, docetaxel (29), and paclitaxel $(28,30)$. The most effective second-line therapy is the combination of ramucirumab and paclitaxel (25). Alternatively, the single-agent option of docetaxel [COUGAR trial (29)] or remucirumab (19) can be selected if toxicity of the combination is projected.

Ramucirumab monotherapy appears feasible for frail patients because of its favorable toxicity profile, although these patients have not been included in the phase III trials (31). Contraindications for ramucirumab include cardiovascular disease, increased thrombotic risk, and oral anticoagulation. If there are contraindications, single-agent taxanes or irinotecan can be used, whereby the adverse event profiles of these drugs will determine the choice of treatment. Diarrhea precludes the administration of irinotecan, while taxanes should not be used for patients with neuropathy grade $>1$. There is solid evidence that only patients with good performance status benefit from second-line treatments. No specific statements can be made for patients with poor performance status, as these patients were not included in the trials $(25-29,31)$.

Switching between docetaxel and paclitaxel as first-line and second-line treatments might be an option, as there is no complete cross-resistance between the two taxanes. Potential solutions include the interposing of irinotecan into the secondline treatment, as well as a time interval of at least 6 months.

Second-line treatment of HER2-positive disease. The continuation of trastuzumab treatment beyond progression is not an established approach in gastric cancer due to a negative randomized trial (32). Reductions in HER2 overexpression are most likely due to the selection of HER2negative clones after first-line treatment with trastuzumab $(33,34)$. Rechallenge of trastuzumab after tumor progression in individual patients can only be based on a second positive HER2 test prior to treatment but is not supported by prospective data (32).

Therefore, the second-line treatment of HER2-positive patients is currently the same as that of HER2-negative patients.

Third-line treatment. Results from the clinical phase III trial TAGS have demonstrated that trifulridin/tipiracil is an active third-line option that will not induce response, but can provide disease stabilization along with significant PFS and OS benefits $(35,36)$. This has led to approval of this drug by the U.S. Food and Drug Administration, while this option was submitted for approval to the European Medical Association. Trifulridin/tipiracil has been in use in the colorectal cancer setting for a long time; its use is thus well established, and it is easy to handle. Therefore, trifulridin/tipiracil is a valid option in patients with progressive disease in later lines with ECOG PS of 0 or 1.

The ATTRACTION-2 trial demonstrated superiority of nivolumab over placebo, thus introducing nivolumab as another third-line option. The limitations of ATTRACTION2 included the exclusive Asian origin of the study population. Moreover, the vast majority of these patients had been diagnosed with gastric carcinoma, and they had very good performance status (37).

In Caucasians, trifulridin/tipiracil was investigated in a patient group that had received comparatively fewer previous treatment lines, which better reflects European use. Trifulridin/tipiracil appears to be a favorable option for the all-comer population, which obviously benefits less from checkpoint inhibition than biomarker-selected patients. The biomarkers here include programed death-ligand 1 (PD-L1), high-level microsatellite instability (MSI-H), and combined positivity score (CPS) $\geq 10(38,39)$. However, checkpoint inhibitors are an alternative in this setting. Emerging data indicate heightened responses to certain checkpoint inhibitors in selected patient groups, i.e. those with MSI-H, EpsteinBarr virus-associated tumors, high PD-L1 expression, CPS $>10$, and high tumor mutational burden. In these groups, checkpoint inhibition might be an option even in the early treatment lines, although trial data are lacking. The KEYNOTE-061 and JAVELIN Gastric 300 trials yielded negative results for the comparison of checkpoint inhibitors with established chemotherapy regimens as second-line treatments for unselected patients $(40,41)$. In KEYNOTE 061, however, the subgroup of patients with high CPS benefited from checkpoint inhibition.

The pivotal phase III trial KEYNOTE-062 evaluated pembrolizumab as monotherapy and in combination with 
chemotherapy (cisplatin and either 5-fluorouracil or capecitabine) for the first-line treatment of advanced gastric or gastroesophageal junction adenocarcinoma. In the monotherapy arm of the study, pembrolizumab met a primary endpoint by demonstrating noninferiority to chemotherapy, the current standard of care, for OS in the intention-to-treat population of patients whose tumors expressed PD-L1 (CPS $\geq 1$ ). In the combination arm, pembrolizumab plus chemotherapy was not found to be superior for OS (CPS $\geq 1$ or CPS $\geq 10$ ) or PFS (CPS $\geq 1$ ) compared with chemotherapy alone (42).

In patients with gastric carcinoma, CPS is assessed at certain clinics, while tumor mutational burden is not assessed routinely. The choice of immunotherapy can be based on immune cell positivity or CPS. MSI and the PD-L1 status are easy to assess and are reproducible. Reports show that analysis using polymerase chain reaction is more sensitive in gastric carcinoma than immunohistochemistry; therefore, this is the only situation in which polymerase chain reaction might be used as an add-on to MSI testing. In other tumor types, immunohistochemistry is sufficient. Double assessment using immunohistochemistry and sequencing is common.

Microsatellite instability testing is more important for treatment decisions in the second line than the first line; this can play a role in Tumor Board treatment decisions. In later lines, MSI testing has great importance. MSI assessment does not require specialized centers $(43,44)$.

The experts reported no personal experience or study experience regarding hyperprogression, which occurs infrequently during checkpoint inhibitor therapy for gastric cancer. In contrast, assessment of remission can be difficult due to pseudo-progression.

\section{Conflicts of Interest}

Wöll E.: speaker and advisory fees: Amgen, Astra Zeneca, BMS, Celgen, Ebewe, Eisai, Eli Lilly, Janssen Cilag, Merck, MSD, Pfizer, Ratiopharm, Roche, Sanofi Aventis. Prager G.: Advisory Board: Merck, Serono, Roche, Amgen, Sanofi, Lilly, Servier, Taiho, Bayer, BMS, Celgene, Shire; Institutional financial interests-Clinical Trials: Celgene, Array, Servier, Bayer, BostonBiomedical, Merck, BMS. All other Authors declare no conflict of interest in regard to this study.

\section{Authors' Contributions}

Conception and design: Wöll E; Data analysis and interpretation: All Authors contributed equally; Manuscript writing: Wöll E; Final approval of article and corrections: All Authors contributed equally.

\section{Acknowledgements}

The Authors thank Dr. Judith Moser for providing writing assistance. Publication of this review was supported by a grant of Verein für Tumorforschung.

\section{References}

1 Noone AM, Howlader N, Krapcho M, Miller D, Bishop K, Altekruse SF, Kosary CL, Yu M, Ruhl J, Tatalovich Z, Mariotto A, Lewis DR, Chen HS, Feuer EJ and Cronin KA (eds).: SEER cancer statistics review, 1975-2013, National Cancer Institute. Bethesda, MD, USA. Available at: http://seer.cancer.gov/ csr/1975_2013/, based on November 2015 SEER data submission, posted to the SEER web site, April 2016.

2 Wöll E, Devries A, Eisterer W, Hejna M, Keil F, Stein H, Zacherl $\mathrm{J}$ and Greil R: Chemotherapy in gastric cancer. Anticancer Res 28(2B): 1213-1219, 2008. PMID: 18505058.

3 Al-Batran SE, Homann N, Pauligk C, Goetze TO, Meiler J, Kasper S, Kopp HG, Mayer F, Haag GM, Luley K, Lindig U, Schmiegel W, Pohl M, Stoehlmacher J, Folprecht G, Probst S, Prasnikar N, Fischbach W, Mahlberg R, Trojan J, Koenigsmann M, Martens UM, Thuss-Patience P, Egger M, Block A, Heinemann V, Illerhaus G, Moehler M, Schenk M, Kullmann F, Behringer DM, Heike M, Pink D, Teschendorf C, Lohr C, Bernhard H, Schuch G, Rethwisch V, von Weikersthal LF, Hartmann JT, Kneba M, Daum S, Schulmann K, Weniger J, Belle S, Gaiser T, Oduncu FS, Guntner M, Hozaeel W, Reichart A, Jager E, Kraus T, Monig S, Bechstein WO, Schuler M, Schmalenberg H, Hofheinz RD and FLOT4-AIO Investigators: Perioperative chemotherapy with fluorouracil plus leucovorin, oxaliplatin, and docetaxel versus fluorouracil or capecitabine plus cisplatin and epirubicin for locally advanced, resectable gastric or gastro-oesophageal junction adenocarcinoma (FLOT4): A randomised, phase 2/3 trial. Lancet 393(10184): 1948-1957, 2019. PMID: 30982686. DOI: 10.1016/S0140-6736(18)32557-1

4 Al-Batran SE, Hofheinz RD, Pauligk C, Kopp HG, Haag GM, Luley KB, Meiler J, Homann N, Lorenzen S, Schmalenberg H, Probst S, Koenigsmann M, Egger M, Prasnikar N, Caca K, Trojan J, Martens UM, Block A, Fischbach W, Mahlberg R, Clemens M, Illerhaus G, Zirlik K, Behringer DM, Schmiegel W, Pohl M, Heike M, Ronellenfitsch U, Schuler M, Bechstein WO, Konigsrainer A, Gaiser T, Schirmacher P, Hozaeel W, Reichart A, Goetze TO, Sievert M, Jager E, Monig S and Tannapfel A: Histopathological regression after neoadjuvant docetaxel, oxaliplatin, fluorouracil, and leucovorin versus epirubicin, cisplatin, and fluorouracil or capecitabine in patients with resectable gastric or gastro-oesophageal junction adenocarcinoma (FLOT4-AIO): Results from the phase 2 part of a multicentre, open-label, randomised phase 2/3 trial. Lancet Oncol 17(12): 1697-1708, 2016. PMID: 27776843. DOI: 10.1016/S14702045(16)30531-9

5 Cunningham D, Allum WH, Stenning SP, Thompson JN, Van de Velde CJ, Nicolson M, Scarffe JH, Lofts FJ, Falk SJ, Iveson TJ, Smith DB, Langley RE, Verma M, Weeden S and Chua YJ: Perioperative chemotherapy versus surgery alone for resectable gastroesophageal cancer. N Eng1 J Med 355(1): 11-20, 2006. PMID: 16822992. DOI: 10.1056/NEJMoa055531

6 Yoshida K, Kodera Y, Kochi M, Ichikawa W, Kakeji Y, Sano T, Nagao N, Takahashi M, Takagane A, Watanabe T, Kaji M, Okitsu H, Nomura T, Matsui T, Yoshikawa T, Matsuyama J, Yamada $M$, Ito $S$, Takeuchi $M$ and Fujii $M$ : Addition of docetaxel to oral fluoropyrimidine improves efficacy in patients with stage iii gastric cancer: Interim analysis of JACCRO GC07, a randomized controlled trial. J Clin Oncol 37(15): 12961304, 2019. PMID: 30925125. DOI: 10.1200/JCO.18.01138 
7 Vermillion SA, Hsu FC, Dorrell RD, Shen P and Clark CJ: Modified frailty index predicts postoperative outcomes in older gastrointestinal cancer patients. J Surg Oncol 115(8): 997-1003, 2017. PMID: 28437582. DOI: $10.1002 /$ jso. 24617

8 Al-Batran SE, Pauligk C, Homann N, Schmalenberg H, Kopp HG, Haag GM, Luley Kim B, Schmiegel Wolff H, Folprecht G, Probst S, Prasnikar N, Thuss-Patience Peter C, Trojan J, Goetze TO, Meiler J, Schuler Martin H, Jager E and Hofheinz RD: LBA-008 docetaxel, oxaliplatin, and fluorouracil/leucovorin (FLOT) versus epirubicin, cisplatin, and fluorouracil or capecitabine (ECF/ECX) as perioperative treatment of resectable gastric or gastroesophageal junction adenocarcinoma: The multicenter, randomized phase 3 FLOT4 trial (German Gastric Group at AIO). Ann Oncol 28(suppl_3), 2017. DOI: 10.1093/annonc/mdx302.007

9 Smyth EC, Verheij M, Allum W, Cunningham D, Cervantes A, Arnold D and ESMO Guidelines Committee: Gastric cancer: ESMO clinical practice guidelines for diagnosis, treatment and follow-up. Ann Oncol 27(suppl 5): v38-v49, 2016. DOI: 10.1093/annonc/mdw350

10 GASTRIC Group; Paoletti X, Oba K, Burzykowski T, Michiels S, Ohashi Y, Pignon JP, Rougier P, Sakamoto J, Sargent D, Sasako M, Van Cutsem E and Buyse M: Benefit of adjuvant chemotherapy for resectable gastric cancer: A meta-analysis. JAMA 303(17): 1729-1737, 2010. PMID: 20442389. DOI: 10.1001/jama.2010.534

11 Di Bartolomeo M, Buzzoni R, Mariani L, Ferrario E, Katia D, Gevorgyan A, Zilembo N, Bordonaro R, Bochicchio AM, Massidda B, Ardizzoia A, Marini G, Aitini E, Schieppati G, Comella G, Pinotti G, Palazzo S, Cicero G, Bajetta E, Italian Trial in Medical Oncology G, Villa E, Fagnani D, Reguzzoni G, Agostana B, Oliani C, Kildani B, Duro M, Botta M, Mozzana R and Mantovani G: Feasibility of sequential therapy with folfiri followed by docetaxel/cisplatin in patients with radically resected gastric adenocarcinoma. A randomized phase III trial. Oncology 71(5-6): 341-346, 2006. PMID: 17855795. DOI: $10.1159 / 000108575$

12 Cunningham D and Chua YJ: East meets West in the treatment of gastric cancer. N Engl J Med 357(18): 1863-1865, 2007. PMID: 17978296. DOI: 10.1056/NEJMe078182

13 Macdonald JS, Smalley SR, Benedetti J, Hundahl SA, Estes NC, Stemmermann GN, Haller DG, Ajani JA, Gunderson LL, Jessup JM and Martenson JA: Chemoradiotherapy after surgery compared with surgery alone for adenocarcinoma of the stomach or gastroesophageal junction. N Engl J Med 345(10): 725-730, 2001. PMID: 11547741. DOI: 10.1056/NEJMoa010187

14 Cats A, Sikorska K and Verheij M: Adjuvant therapy in resectable gastric cancer-the critics trial - authors' reply. Lancet Oncol 19(7): e331, 2018. DOI: 10.1016/S1470-2045(18)30436-4

15 Slagter AE, Jansen EPM, van Laarhoven HWM, van Sandick JW, van Grieken NCT, Sikorska K, Cats A, Muller-Timmermans P, Hulshof M, Boot H, Los M, Beerepoot LV, Peters FPJ, Hospers GAP, van Etten B, Hartgrink $\mathrm{HH}$, van Berge Henegouwen MI, Nieuwenhuijzen GAP, van Hillegersberg R, van der Peet DL, Grabsch HI and Verheij M: Critics-II: A multicentre randomised phase II trial of neo-adjuvant chemotherapy followed by surgery versus neo-adjuvant chemotherapy and subsequent chemoradiotherapy followed by surgery versus neo-adjuvant chemoradiotherapy followed by surgery in resectable gastric cancer. BMC Cancer 18(1): 877, 2018. PMID: 30200910. DOI: 10.1186/s12885-018-4770-2
16 Park SH, Sohn TS, Lee J, Lim DH, Hong ME, Kim KM, Sohn I, Jung SH, Choi MG, Lee JH, Bae JM, Kim S, Kim ST, Park JO, Park YS, Lim HY and Kang WK: Phase III trial to compare adjuvant chemotherapy with capecitabine and cisplatin versus concurrent chemoradiotherapy in gastric cancer: Final report of the adjuvant chemoradiotherapy in stomach tumors trial, including survival and subset analyses. J Clin Oncol 33(28): 3130-3136, 2015. PMID: 25559811. DOI: 10.1200/JCO. 2014.58.3930

17 van Hagen P, Hulshof MC, van Lanschot JJ, Steyerberg EW, van Berge Henegouwen MI, Wijnhoven BP, Richel DJ, Nieuwenhuijzen GA, Hospers GA, Bonenkamp JJ, Cuesta MA, Blaisse RJ, Busch OR, ten Kate FJ, Creemers GJ, Punt CJ, Plukker JT, Verheul HM, Spillenaar Bilgen EJ, van Dekken H, van der Sangen MJ, Rozema T, Biermann K, Beukema JC, Piet AH, van Rij CM, Reinders JG, Tilanus HW, van der Gaast A and CROSS Group: Preoperative chemoradiotherapy for esophageal or junctional cancer. N Engl J Med 366(22): 2074-2084, 2012. PMID: 22646630. DOI: 10.1056/NEJMoa1112088

18 Wöll ER, Regitnig P, Eisterer W, Thaler J, OexleH, Hartmann B, Andel J, Wuestner A, Jagdt B, Tinchon C, Fridrik M and Greil R: Prospective screening for human epidermal growth factor receptor 2 (HER2) positivity in patients with inoperable locally advanced or metastatic gastric or gastro-esophageal junction cancer. Agmt gastric-5. J Clin Oncol 34(suppl): abstr. e15501, 2016. DOI: 10.1200/JCO.2016.34.15_suppl.e15501

19 Lordick F, Arnold D, Borner M, Bruns CJ, Eisterer W, Faber G, Hegewisch-Becker S, Möhler M, Pritzkuleit R, Stahl M, ThussPatience P and Wöll E: Onkopedia leitlinien magenkarzinom. Onkopedia, 2018. Available at: https://www.onkopedia.com/ de/onkopedia/guidelines/magenkarzinom/@@guideline/html/index. html

20 Moehler M, Al-Batran SE, Andus T, Anthuber M, Arends J, Arnold D, Aust D, Baier P, Baretton G, Bernhardt J, Boeing H, Bohle E, Bokemeyer C, Bornschein J, Budach W, Burmester E, Caca K, Diemer WA, Dietrich CF, Ebert M, Eickhoff A, Ell C, Fahlke J, Feussner H, Fietkau R, Fischbach W, Fleig W, Flentje M, Gabbert HE, Galle PR, Geissler M, Gockel I, Graeven U, Grenacher L, Gross S, Hartmann JT, Heike M, Heinemann V, Herbst B, Herrmann T, Hocht S, Hofheinz RD, Hofler H, Hohler T, Holscher AH, Horneber M, Hubner J, Izbicki JR, Jakobs R, Jenssen C, Kanzler S, Keller M, Kiesslich R, Klautke G, Korber J, Krause BJ, Kuhn C, Kullmann F, Lang H, Link H, Lordick F, Ludwig K, Lutz M, Mahlberg R, Malfertheiner P, Merkel S, Messmann H, Meyer HJ, Monig S, Piso P, Pistorius S, Porschen R, Rabenstein T, Reichardt P, Ridwelski K, Rocken C, Roetzer I, Rohr P, Schepp W, Schlag PM, Schmid RM, Schmidberger H, Schmiegel WH, Schmoll HJ, Schuch G, Schuhmacher C, Schutte K, Schwenk W, Selgrad M, Sendler A, Seraphin J, Seufferlein T, Stahl M, Stein H, Stoll C, Stuschke M, Tannapfel A, Tholen R, Thuss-Patience P, Treml K, Vanhoefer U, Vieth M, Vogelsang $\mathrm{H}$, Wagner D, Wedding U, Weimann A, Wilke H, Wittekind C and AWMF: German S3-guideline "diagnosis and treatment of esophagogastric cancer". Z Gastroenterol 49(4): 461-531, 2011. DOI: $10.1055 / \mathrm{s}-0031-1273201$ (in German).

21 Wagner AD, Grothe W, Haerting J, Kleber G, Grothey A and Fleig WE: Chemotherapy in advanced gastric cancer: A systematic review and meta-analysis based on aggregate data. J Clin Oncol 24(18): 2903-2909, 2006. PMID: 16782930. DOI: 10.1200/JCO.2005.05.0245 
22 Lorenzen S, Pauligk C, Homann N, Schmalenberg H, Jager E and Al-Batran SE: Feasibility of perioperative chemotherapy with Infusional 5-FU, leucovorin, and oxaliplatin with (FLOT) or without (FLO) docetaxel in elderly patients with locally advanced esophagogastric cancer. Br J Cancer 108(3): 519-526, 2013. PMID: 23322206. DOI: 10.1038/bjc.2012.588

23 Al-Batran S , Kroening H, Hannig CV, Hamm T, Moorahrend E, Petersen V, Eggers E, Hempel D, Zielke K, Wohlfarth T, ThussPatience PC, Moehler M and Hegewisch-Becker S: Trastuzumab in combination with different first-line chemotherapies for treatment of HER2-positive metastatic gastric cancer: Updated findings from the German non-interventional study Hermes. Ann Oncol 25(Suppl 4), 2014. DOI: https://doi.org/10.1093/ annonc/mdu334.27

24 Bang YJ, Van Cutsem E, Feyereislova A, Chung HC, Shen L, Sawaki A, Lordick F, Ohtsu A, Omuro Y, Satoh T, Aprile G, Kulikov E, Hill J, Lehle M, Ruschoff J and Kang YK: Trastuzumab in combination with chemotherapy versus chemotherapy alone for treatment of HER2-positive advanced gastric or gastro-oesophageal junction cancer (TOGA): A phase 3, open-label, randomised controlled trial. Lancet 376(9742): 687-697, 2010. PMID: 20728210. DOI: 10.1016/S0140-6736(10)61121-X

25 Wilke H, Muro K, Van Cutsem E, Oh SC, Bodoky G, Shimada Y, Hironaka S, Sugimoto N, Lipatov O, Kim TY, Cunningham D, Rougier P, Komatsu Y, Ajani J, Emig M, Carlesi R, Ferry D, Chandrawansa K, Schwartz JD and Ohtsu A: Ramucirumab plus paclitaxel versus placebo plus paclitaxel in patients with previously treated advanced gastric or gastro-oesophageal junction adenocarcinoma (RAINBOW): A double-blind, randomised phase 3 trial. Lancet Oncol 15(11): 1224-1235, 2014. PMID: 25240821. DOI: 10.1016/S1470-2045(14)70420-6

26 Fuchs CS, Tomasek J, Yong CJ, Dumitru F, Passalacqua R, Goswami C, Safran H, dos Santos LV, Aprile G, Ferry DR, Melichar B, Tehfe M, Topuzov E, Zalcberg JR, Chau I, Campbell W, Sivanandan C, Pikiel J, Koshiji M, Hsu Y, Liepa AM, Gao L, Schwartz JD and Tabernero J: Ramucirumab monotherapy for previously treated advanced gastric or gastrooesophageal junction adenocarcinoma (REGARD): An international, randomised, multicentre, placebo-controlled, phase 3 trial. Lancet 383(9911): 31-39, 2014. PMID: 24094768. DOI: 10.1016/S0140-6736(13)61719-5

27 Thuss-Patience PC, Kretzschmar A, Bichev D, Deist T, Hinke A, Breithaupt K, Dogan Y, Gebauer B, Schumacher G and Reichardt P: Survival advantage for irinotecan versus best supportive care as second-line chemotherapy in gastric cancer-a randomised phase III study of the Arbeitsgemeinschaft Internistische Onkologie (AIO). Eur J Cancer 47(15): 23062314, 2011. PMID: 21742485. DOI: 10.1016/j.ejca.2011.06.002

28 Hironaka S, Ueda S, Yasui H, Nishina T, Tsuda M, Tsumura T, Sugimoto N, Shimodaira H, Tokunaga S, Moriwaki T, Esaki T, Nagase M, Fujitani K, Yamaguchi K, Ura T, Hamamoto Y, Morita $\mathrm{S}$, Okamoto I, Boku N and Hyodo I: Randomized, open-label, phase III study comparing irinotecan with paclitaxel in patients with advanced gastric cancer without severe peritoneal metastasis after failure of prior combination chemotherapy using fluoropyrimidine plus platinum: WJOG 4007 trial. J Clin Oncol 31(35): 4438-4444, 2013. PMID: 24190112. DOI: 10.1200/ JCO.2012.48.5805

29 Ford HE, Marshall A, Bridgewater JA, Janowitz T, Coxon FY, Wadsley J, Mansoor W, Fyfe D, Madhusudan S, Middleton GW, Swinson D, Falk S, Chau I, Cunningham D, Kareclas P, Cook
N, Blazeby JM, Dunn JA and Cougar-Investigators: Docetaxel versus active symptom control for refractory oesophagogastric adenocarcinoma (COUGAR-02): An open-label, phase 3 randomised controlled trial. Lancet Oncol 15(1): 78-86, 2014. PMID: 24332238. DOI: 10.1016/S1470-2045(13)70549-7

30 Kang JH, Lee SI, Lim DH, Park KW, Oh SY, Kwon HC, Hwang IG, Lee SC, Nam E, Shin DB, Lee J, Park JO, Park YS, Lim HY, Kang WK and Park SH: Salvage chemotherapy for pretreated gastric cancer: A randomized phase iii trial comparing chemotherapy plus best supportive care with best supportive care alone. J Clin Oncol 30(13): 1513-1518, 2012. PMID: 22412140. DOI: $10.1200 / J C O .2011 .39 .4585$

31 Fuchs CS, Tomasek J, Yong CJ, Dumitru F, Passalacqua R, Goswami C, Safran H, dos Santos LV, Aprile G, Ferry DR, Melichar B, Tehfe M, Topuzov E, Zalcberg JR, Chau I, Campbell W, Sivanandan C, Pikiel J, Koshiji M, Hsu Y, Liepa AM, Gao L, Schwartz JD, Tabernero J and REGARD Trial Investigators: Ramucirumab monotherapy for previously treated advanced gastric or gastro-oesophageal junction adenocarcinoma (REGARD): An international, randomised, multicentre, placebocontrolled, phase 3 trial. Lancet 383(9911): 31-39, 2014. DOI: 10.1016/S0140-6736(13)61719-5

32 Makiyama A, Sagara K, Kawada J, Kashiwada T, Hosokawa A, Horie Y, Satake H, Yamamoto Y, Tanioka H, Shinozaki K, Nishikawa K, Uchino K, Sukawa Y, Yamanaka T, Yamazaki K, Hironaka S, Boku N, Hyodo I, Esaki $\mathrm{T}$ and Muro $\mathrm{K}$ : A randomized phase II study of weekly paclitaxel \pm trastuzumab in patients with HER2-positive advanced gastric or gastroesophageal junction cancer refractory to trastuzumab combined with fluoropyrimidine and platinum: WJOG7112G (T-ACT). J Clin Oncol 36(suppl): abstr 4011, 2018. DOI: $10.1200 / \mathrm{JCO}$. 2018.36.15_suppl.4011

33 Seo S, Ryu MH, Park YS, Ahn JY, Park Y, Park SR, Ryoo BY, Lee GH, Jung HY and Kang YK: Loss of HER2 positivity after anti-HER2 chemotherapy in HER2-positive gastric cancer patients: Results of the gastric cancer HER2 reassessment study 3 (GASTHER3). Gastric Cancer, 2018. PMID: 30386954. DOI: 10.1007/s10120-018-0891-1

34 Saeki H, Oki E, Kashiwada T, Arigami T, Makiyama A, Iwatsuki M, Narita Y, Satake H, Matsuda Y, Sonoda H, Shimokawa M, Maehara Y and Kyushu Study Group of Clinical Cancer (KSCC): Re-evaluation of HER2 status in patients with HER2positive advanced or recurrent gastric cancer refractory to trastuzumab (KSCC1604). Eur J Cancer 105: 41-49, 2018. PMID: 30391779. DOI: 10.1016/j.ejca.2018.09.024

35 Bando H, Doi T, Muro K, Yasui H, Nishina T, Yamaguchi K, Takahashi S, Nomura S, Kuno H, Shitara K, Sato A and Ohtsu A: A multicenter phase II study of TAS-102 monotherapy in patients with pre-treated advanced gastric cancer (EPOC1201). Eur J Cancer 62: 46-53, 2016. PMID: 27208903. DOI: 10.1016/ j.ejca.2016.04.009

36 Shitara K, Doi T, Dvorkin M, Mansoor W, Arkenau HT, Prokharau A, Alsina M, Ghidini M, Faustino C, Gorbunova V, Zhavrid E, Nishikawa K, Hosokawa A, Yalcin S, Fujitani K, Beretta GD, Cutsem EV, Winkler RE, Makris L, Ilson DH and Tabernero J: Trifluridine/tipiracil versus placebo in patients with heavily pretreated metastatic gastric cancer (TAGS): A randomised, double-blind, placebo-controlled, phase 3 trial. Lancet Oncol 19(11): 1437-1448, 2018. PMID: 30355453. DOI: $10.1016 / \mathrm{S} 1470-2045(18) 30739-3$ 
37 Kang YK, Boku N, Satoh T, Ryu MH, Chao Y, Kato K, Chung HC, Chen JS, Muro K, Kang WK, Yeh KH, Yoshikawa T, Oh SC, Bai LY, Tamura T, Lee KW, Hamamoto Y, Kim JG, Chin K, Oh DY, Minashi K, Cho JY, Tsuda M and Chen LT: Nivolumab in patients with advanced gastric or gastro-oesophageal junction cancer refractory to, or intolerant of, at least two previous chemotherapy regimens (ONO-4538-12, ATTRACTION-2): A randomised, double-blind, placebo-controlled, phase 3 trial. Lancet 390(10111): 2461-2471, 2017. PMID: 28993052. DOI: $10.1016 / \mathrm{S} 0140-6736(17) 31827-5$

38 The Cancer Genome Atlas Research Network: Comprehensive molecular characterization of gastric adenocarcinoma. Nature 513(7517): 202-209, 2014. PMID: 25079317. DOI: 10.1038/ nature 13480

39 Kim ST, Cristescu R, Bass AJ, Kim KM, Odegaard JI, Kim K, Liu XQ, Sher X, Jung H, Lee M, Lee S, Park SH, Park JO, Park YS, Lim HY, Lee H, Choi M, Talasaz A, Kang PS, Cheng J, Loboda A, Lee J and Kang WK: Comprehensive molecular characterization of clinical responses to PD-1 inhibition in metastatic gastric cancer. Nat Med 24(9): 1449-1458, 2018. PMID: 30013197. DOI: 10.1038/s41591-018-0101-z

40 Shitara K, Ozguroglu M, Bang YJ, Di Bartolomeo M, Mandala M, Ryu MH, Fornaro L, Olesinski T, Caglevic C, Chung HC, Muro K, Goekkurt E, Mansoor W, McDermott RS, ShachamShmueli E, Chen X, Mayo C, Kang SP, Ohtsu A, Fuchs CS and KEYNOTE-061 investigators: Pembrolizumab versus paclitaxel for previously treated, advanced gastric or gastrooesophageal junction cancer (KEYNOTE-061): A randomised, open-label, controlled, phase 3 trial. Lancet 392(10142): 123133, 2018. PMID: 29880231. DOI: 10.1016/S0140-6736(18) $31257-1$
41 Bang YJ, Ruiz EY, Van Cutsem E, Lee KW, Wyrwicz L, Schenker M, Alsina M, Ryu MH, Chung HC, Evesque L, AlBatran SE, Park SH, Lichinitser M, Boku N, Moehler MH, Hong J, Xiong H, Hallwachs R, Conti I and Taieb J: Phase III, randomised trial of avelumab versus physician's choice of chemotherapy as third-line treatment of patients with advanced gastric or gastro-oesophageal junction cancer: Primary analysis of JAVELIN GASTRIC 300. Ann Oncol 29(10): 2052-2060, 2018. PMID: 30052729. DOI: 10.1093/annonc/mdy264

42 Tabernero J, Cutsem EV, Bang Y-J, Fuchs CS, Wyrwicz L, Lee KW, Kudaba I, Garrido M, Chung HC, Salguero H, Mansoor W, Braghiroli M, Goekkurt E, Chao J, Wainberg Z, Kher U, Shah S, Kang S and Shitara S: Pembrolicumab with or without chemotherapy for advanced gastric or gastrooesophageal junction (G/GEJ) adenocarcinoma: The phase iii keynote-062 study. J Clin Oncol 37(suppl): abstr LBA 4007, 2019. DOI: 10.1200/JCO.2019.37.18_suppl.LBA4007

43 Shen H, Zhong M, Wang W, Liao P, Yin X, Rotroff D, Knepper TC, McLeod HL, Zhou C, Xie S, Li W, Xu B and He Y: EBV infection and MSI status significantly influence the clinical outcomes of gastric cancer patients. Clin Chim Acta 471: 216221, 2017. PMID: 28601671. DOI: 10.1016/j.cca.2017.06.006

44 De Rosa S, Sahnane N, Tibiletti MG, Magnoli F, Vanoli A, Sessa $\mathrm{F}$ and Chiaravalli $\mathrm{AM}: \operatorname{EBV}(+)$ and MSI gastric cancers harbor high PD-L1/PD-1 expression and high CD8(+) intratumoral lymphocytes. Cancers 10(4): 102, 2018. PMID: 29614789. DOI: $10.3390 /$ cancers 10040102

Received June 2, 2019

Revised July 15, 2019

Accepted July 19, 2019 